Research Article

\title{
Cost analysis of antiepileptic drugs available in India
}

\author{
Ajay Kumar Shukla ${ }^{1}$, Rekha Mehani ${ }^{2}$
}

\begin{abstract}
${ }^{1}$ Department of Pharmacology, Gandhi Medical College, Bhopal, Madhya |Pradesh, India, ${ }^{2}$ Department of Pharmacology, RKDF MCH and RC, Bhopal, Madhya Pradesh, India
\end{abstract}

Received: 14 June 2016 Accepted: 08 July 2016

*Correspondence to: Dr. Ajay Kumar Shukla, Email: drajay1024@gmail.com

Copyright: (C) the author(s), publisher and licensee Medip Academy. This is an openaccess article distributed under the terms of the Creative Commons Attribution NonCommercial License, which permits unrestricted noncommercial use, distribution, and reproduction in any medium, provided the original work is properly cited.

\begin{abstract}
Background: Epilepsy is one of the major causes of morbidity, mortality and needs long-term treatment. There is a wide range of variation in the prices of drugs marketed in India. Thus, a study was planned to analyse out cost variations of antiepileptic drugs available in Indian market.

Methods: Minimum and maximum costs in rupees (INR) of antiepileptic agents manufactured by different companies, in the same strength and dosage forms were obtained from "current index of medical specialties" January - April 2016. The cost ratio and percentage cost variation were calculated for each generic antiepileptic agent.

Results: There is a wide variation in the prices of different brands of same antiepileptic agent in Indian market. The highest cost ratio and percent cost variation was found for divalproex $500 \mathrm{mg}$ [(1:3.17) and 216.7], followed by lamotrigine $25 \mathrm{mg}$ [(1:2.5) and 150], clobazam $10 \mathrm{mg}$ [(1:2.47) and 147.3] and clonazepam $0.5 \mathrm{mg}[(1: 2.46)$ and 145.9].

Conclusions: The average percentage price variation of different brands of the same oral antiepileptic drugs in Indian market is very wide. Treatment of epilepsy has a long course with compliance being a key factor for successful treatment. Improved adherence to the treatment can be ensured by decreasing the cost of therapy, by changes in the government policies and regulations and creating awareness among treating physicians for switching to cost effective therapy.
\end{abstract}

Keywords: Cost analysis, Compliance, Adherence, Epilepsy, Health Economics, Cost variation

\section{INTRODUCTION}

About 50 million people worldwide are suffering from epilepsy. ${ }^{1}$ There are about 10 million persons with epilepsy (PWE) in India. In Indian population, prevalence of epilepsy is about $1 \% .^{2}$ Epilepsy is a condition that has been found to be associated with large treatment gap. Poverty and poor health infrastructure has been found to be contributory to this large treatment gap. ${ }^{1}$

Epilepsy is one of the major causes of morbidity, mortality and needs long-term treatment. Epilepsy describes a condition in which a person has recurrent seizures due to a chronic, underlying process. This definition implies that a person with a single seizure, or recurrent seizures due to correctable or avoidable circumstances, does not necessarily have epilepsy. ${ }^{3}$
The treatment of epilepsy is a challenging task while selecting an appropriate drug or a combination of drugs that controls seizures most effectively at an acceptable level of adverse effects. ${ }^{4}$ Treatment of seizure disorder is almost always multimodal which includes suppression of recurrent seizures by prophylactic therapy with antiepileptic medications. ${ }^{3}$ Once the treatment of epilepsy is initiated, antiepileptic drugs are typically continued for at least two years. Tapering and discontinuing of antiepileptic drugs should be considered, if the patient has been seizure free for at least two years. Complete control of seizures in nearly $50 \%$ of patients is seen with an adherence to single drug treatment. ${ }^{4}$

Inappropriate antiepileptic drug withdrawal leads to increased seizure frequency and severity. ${ }^{5}$ Medication adherence is an important factor to achieve and maintain 
effective plasma concentrations of antiepileptic drugs. ${ }^{6}$ Hence, it can be concluded that medication adherence is a critical contributor to successful treatment of epilepsy.

In Indian market, there are large numbers of branded formulations for every drug molecule. Variable pricing between the different brands of the same formulation is widely prevalent in Indian drug market. ${ }^{7}$

Today's cost-sensitive healthcare environment has created a competitive and challenging workplace for clinicians. Competition for diminishing resources has necessitated that the appraisal of healthcare goods and services extends beyond evaluations of safety and efficacy and considers the economic impact of these goods and services on the cost of healthcare. A challenge for healthcare professionals is to provide quality patient care while assuring an efficient use of resources. ${ }^{8}$

In India, majority of the health costs are afforded by the patients. High medical care costs should be a cause of concern for policy makers and service providers. ${ }^{9}$ Clinicians usually do not appreciate the difference between inexpensive and expensive drugs. This can be attributed to their ignorance about the drug cost along with the tendency to overestimating the cost of inexpensive drugs while underestimating the price of expensive ones. This can result in increased overall drug expenditures. ${ }^{10}$

This study was aimed at investigating and comparing the cost differences in various brands of the same generic agent, so that we can analyse cost variations of antiepileptic drugs. This awareness of cost variation of antiepileptic drugs can be applied for more economical treatment regimen to improve the patient compliance and decreasing the rate of failure of therapy.

\section{METHODS}

The prices of 12 oral antiepileptic drugs, available in 34 different formulations were analysed.

- Cost of a particular drug (cost per 10 tablets), in the same strength and dosage forms being manufactured by different companies was obtained from "current index of medical specialties" (CIMS) January-April 2016.

- The drugs being manufactured by only one company were excluded.

- The cost ratio, the ratio of the cost of the costliest to cheapest brand of the same generic antiepileptic drug was calculated. From this we can know that how many times costliest brand costs more than the cheapest brand in each generic group.

- Percentage cost variation was calculated as follows. ${ }^{11}$

$$
\text { Cost variation }(\%)=\frac{\text { Max. cost }- \text { Min. Cost }}{\text { Min. } \operatorname{cost}} \times 100
$$

\section{RESULTS}

This study shows that there is a wide variation in the prices of different brands of same antiepileptic agent in Indian market. The highest cost ratio (1:3.17) and percent cost variation (216.7) was found for divalproex $500 \mathrm{mg}$, followed by lamotrigine $25 \mathrm{mg}[(1: 2.5)$ and 150], clobazam $10 \mathrm{mg}$ [(1:2.47) and 147.3] and clonazepam 0.5 $\mathrm{mg}[(1: 2.46)$ and 145.9] (Table 1).

Highest number of brands of antiepileptic drugs available in Indian market are for clonazepam $0.5 \mathrm{mg}$ (27) followed by divalproex $500 \mathrm{mg}$ (25) (Table 2).

Table 1: Variation in cost of antiepileptic drugs.

\begin{tabular}{|c|c|c|c|c|c|}
\hline Antiepileptic drug & Strength (mg) & Min. cost (INR) & Max. cost (INR) & Cost ratio & $\%$ cost variation \\
\hline \multirow{2}{*}{ Carbamazepine } & 100 & 6.50 & 9.64 & 1.48 & 48.3 \\
\hline & 200 & 12.10 & 27.20 & 2.25 & 124.8 \\
\hline \multirow{3}{*}{ Clobazam } & 5 & 23.00 & 53.52 & 2.33 & 132.7 \\
\hline & 10 & 43.00 & 106.37 & 2.47 & 147.3 \\
\hline & 20 & 115.48 & 124.70 & 1.08 & 7.98 \\
\hline \multirow{4}{*}{ Clonzepam } & 0.25 & 10.00 & 20.35 & 2.03 & 103.5 \\
\hline & 0.5 & 14.64 & 36.00 & 2.46 & 145.9 \\
\hline & 1 & 24.00 & 43.00 & 1.79 & 79.2 \\
\hline & 2 & 38.00 & 67.00 & 1.76 & 76.3 \\
\hline \multirow{5}{*}{ Divalproex } & 200 & 29.50 & 41.50 & 1.40 & 40.7 \\
\hline & 250 & 32 & 56 & 1.75 & 75 \\
\hline & 300 & 27.3 & 62.5 & 2.29 & 128.9 \\
\hline & 500 & 60 & 190 & 3.17 & 216.7 \\
\hline & 750 & 90.00 & 105.00 & 1.17 & 16.6 \\
\hline Gabapentin & 300 & 69.90 & 110.00 & 1.57 & 57.4 \\
\hline \multirow{2}{*}{ Lamotrigine } & 25 & 20.00 & 50.00 & 2.5 & 150 \\
\hline & 50 & 37.50 & 90.00 & 2.4 & 140 \\
\hline
\end{tabular}




\begin{tabular}{|llllll|}
\hline & 100 & 66.25 & 157.00 & 2.37 & 136.9 \\
\hline \multirow{3}{*}{ Levetiracetam } & 250 & 44.00 & 99.00 & 2.25 & 125 \\
& 500 & 75.00 & 164.00 & 2.18 & 118.6 \\
\cline { 2 - 6 } & 750 & 115.00 & 246.00 & 2.13 & 113.9 \\
\hline \multirow{3}{*}{ Oxcarbazepine } & 150 & 26.39 & 43.00 & 1.63 & 62.9 \\
& 300 & 48.33 & 70.00 & 1.45 & 44.8 \\
\cline { 2 - 6 } Phenytoin & 600 & 90.00 & 134.00 & 1.49 & 48.9 \\
& 50 & 6.72 & 10.46 & 1.56 & 55.6 \\
\hline \multirow{2}{*}{ Pregabalin } & 15.00 & 21.10 & 1.41 & 40.7 \\
\hline \multirow{2}{*}{ Topiramate } & 300 & 38.91 & 56.66 & 1.46 & 45.6 \\
\hline \multirow{2}{*}{ Valproic acid } & 75 & 56.83 & 96.75 & 1.70 & 70.2 \\
\hline
\end{tabular}

Table 2: Brands and formulations of antiepileptic drugs.

\begin{tabular}{|c|c|c|c|}
\hline $\begin{array}{l}\text { Antiepileptic } \\
\text { drug }\end{array}$ & Formulations & $\begin{array}{l}\text { Strength } \\
\text { (mg) }\end{array}$ & Brands \\
\hline \multirow{2}{*}{ Carbamazepine } & \multirow{2}{*}{2} & 100 & 4 \\
\hline & & 200 & 9 \\
\hline \multirow{3}{*}{ Clobazam } & \multirow{3}{*}{3} & 5 & 7 \\
\hline & & 10 & 9 \\
\hline & & 20 & 2 \\
\hline \multirow{4}{*}{ Clonzepam } & \multirow{4}{*}{4} & 0.25 & 15 \\
\hline & & 0.5 & 27 \\
\hline & & 1 & 15 \\
\hline & & 2 & 16 \\
\hline \multirow{5}{*}{ Divalproex } & \multirow{5}{*}{5} & 200 & 10 \\
\hline & & 250 & 11 \\
\hline & & 300 & 10 \\
\hline & & 500 & 25 \\
\hline & & 750 & 7 \\
\hline \multirow{2}{*}{ Gabapentin } & \multirow{2}{*}{2} & 100 & 2 \\
\hline & & 300 & 4 \\
\hline \multirow{3}{*}{ Lamotrigine } & \multirow{3}{*}{3} & 25 & 4 \\
\hline & & 50 & 4 \\
\hline & & 100 & 4 \\
\hline \multirow{3}{*}{ Levetiracetam } & \multirow{3}{*}{3} & 250 & 8 \\
\hline & & 500 & 9 \\
\hline & & 750 & 7 \\
\hline \multirow{3}{*}{ Oxcarbazepine } & \multirow{3}{*}{3} & 150 & 8 \\
\hline & & 300 & 9 \\
\hline & & 600 & 8 \\
\hline \multirow{3}{*}{ Phenytoin } & \multirow{3}{*}{3} & 50 & 4 \\
\hline & & 100 & 6 \\
\hline & & 300 & 3 \\
\hline \multirow{2}{*}{ Pregabalin } & \multirow[b]{2}{*}{2} & 75 & 12 \\
\hline & & 150 & 8 \\
\hline \multirow{2}{*}{ Topiramate } & \multirow[b]{2}{*}{2} & 25 & 3 \\
\hline & & 50 & 4 \\
\hline \multirow{2}{*}{ Valproic acid } & \multirow{2}{*}{2} & 200 & 9 \\
\hline & & 500 & 8 \\
\hline
\end{tabular}

\section{DISCUSSION}

In our study, we found that there is a wide variation in the prices of different brands of same antiepileptic agent in Indian market. The highest cost ratio and percent cost variation was found for divalproex $500 \mathrm{mg}$, followed by lamotrigine $25 \mathrm{mg}$, clobazam $10 \mathrm{mg}$ and clonazepam 0.5 $\mathrm{mg}$. Antiepileptic drug with maximum number of brands are clonazepam $0.5 \mathrm{mg}$ (27) followed by divalproex 500 $\mathrm{mg}(25)$.

Higher medication costs have been found to be a reason for medication nonadherence. ${ }^{12}$

Cost related poor medication adherence has been found to be related to adverse health outcomes. ${ }^{13}$ Medication noncompliance can be the single most common reason for treatment failure in epilepsy. It is estimated that up to $60 \%$ of patients with epilepsy are noncompliant. Noncompliance is not influenced by age, sex, psychomotor development, or seizure type. ${ }^{14}$

Increasing patient cost sharing was associated with declines in medication adherence, which in turn was associated with poorer health outcomes. ${ }^{15}$ Decreased drug cost has been associated with improved adherence to the medication regimen. ${ }^{16}$ Non-compliance of the drug therapy results in progression of the disease which increases the overall medical care costs dramatically.

Treatment with generic AEDs have been found to have fewer adverse seizure-related clinical outcomes and improved treatment adherence than treatment with brand name versions. ${ }^{17}$

The price of medicines has been found to be linked to their marketing strategies. No correlation has been found between the quality of the medicine and its corresponding price. ${ }^{18}$ Thus, it appears essential that the huge difference between the pricing of brands have to be regulated by concerned agencies. 
There is a lack of appreciation among the doctors about the degree of cost variation of drugs. Doctors have the tendency to overestimate the price of inexpensive drugs and underestimate the price of expensive ones. This ultimately results in increased overall drug expenditures. ${ }^{10}$ Prescribing doctors should pay due importance to the drug prices in a country like India where majority of patients are paying out of their pockets for their medical bills and are not covered by insurance schemes. ${ }^{19}$ More than $80 \%$ health financing is borne by patients in India. ${ }^{20}$

Pharmacoeconomics should be an integral part of undergraduate and postgraduate medical education curriculum. This will foster their awareness about the impact of cost of therapy on the medication adherence and successful treatment of the disease. Physician's awareness about the cost differences should be ensured by providing a manual of comparative drug prices. Availability of manual has been found to reduce patient's drug expense. ${ }^{21}$

Currently, very few medicines are under drug prices control order. Government should bring more number of antiepileptic drugs under price control. Due consideration must be placed on antiepileptic drugs to increase their accessibility to common people. DPCO is an effective tool for regulation of drug prices. Thus, this study highlights that there exists a huge and variable price variation among the antiepileptic drugs manufactured by different companies. Strong measures must be taken by the government and concerned agencies for uniformity in drug pricing.

\section{CONCLUSION}

The average percentage price variation of different brands of the same oral antiepileptic drugs in Indian market is very wide. Treatment of epilepsy has a long course with compliance being a key factor for successful treatment. Increased adherence to the treatment can be ensured by decreasing the cost of therapy, by changes in the government policies and regulations and creating awareness among treating physicians for switching to cost effective therapy.

\section{Funding: No funding sources}

Conflict of interest: None declared

Ethical approval: Not required

\section{REFERENCES}

1. Santhosh NS, Sinha S, Satishchandra P. Epilepsy: Indian perspective. Annals of Indian Academy of Neurology. 2014;17(Suppl 1):S3-S11.

2. Sridharan R, Murthy BN. Prevalence and pattern of epilepsy in India. Epilepsia.1999;40:631-6.

3. Lowenstein DH. Seizures and Epilepsy. In: Longo DL, Fauci AS, Kasper DL, Hauser SL, Jameson J,
Loscalzo J. eds. Harrison's Principles of Internal Medicine, $19^{\text {th }}$ ed. New York, NY: McGraw-Hill; 2015:2542-2559.

4. McNamara JO. Pharmacotherapy of the epilepsies. In: Brunton LB, Chabner BA, Knollman BC, eds. Goodman and Gilman's The Pharmacological Basis of Therapeutics.12 ${ }^{\text {th }}$ ed. New York, NY: McGrawHill; 2011:583-606.

5. Porter RJ, Meldrum BS. Antiseizure drugs. In: Katzung BC, Trevor AJ. Basic and Clinical Pharmacology. $13^{\text {th }}$ ed. New York, NY: McGrawHill; 2015:566.

6. Boylan L, Gagne J. Nonequivalence of equivalence methods. Ann Neurol. 2012;71(2):284-5.

7. Das SC, Mandal M, Mandal SC. A critical study on availability and price variation between different brands: impact on access to medicines. Indian J Pharm Sci. 2007;69(1):160-3.

8. Pharmacoeconomics: Principles, Methods, and Applications. DiPiro JT, Lamber RL, Yee GC, Matzke GR, Wells BG, Posey LM. Pharmacotherapy: a Pathophysiologic Approach. $19^{\text {th }}$ e. New York, NY: McGraw-Hill; 2011:01.

9. Gupta SK. Proposed pharmacoeconomics guidelines for India (PEG-I). IPSOR India Chapter; 2013:79100.

10. Allan GM, Lexchin J, Wiebe N. Physician awareness of drug cost: a systematic review. PLoS Med. 2007;4(9):e283.

11. Jana S, Mondal P. Pharmacoeconomics: the need to sensitize undergraduate medical students. Indian $\mathbf{J}$ Pharmacol. 2005;37(5):277-8.

12. Shrank WH, Hoang T, Ettner SL, Glassman PA, Nair $\mathrm{K}$, DeLapp D, et al. The implications of choice: prescribing generic or preferred pharmaceuticals improves medication adherence for chronic conditions. Arch Intern Med. 2006;166(3):332-7.

13. Akila L, Rani RJ. Cost analysis of different brands of antianginal drugs available in India. Int J Basic Clin Pharmacol. 2015;4:860-3.

14. Ho PM, Bryson CL, Rumsfeld JS. Medication adherence: its importance in cardiovascular outcomes. Circulation. 2009;119:3028-35.

15. Mojtabai R, Olfson M. Medication costs, adherence, and health outcomes among medicare beneficiaries. Health Affairs. 2003;22(4):220-9.

16. Garnett WR. Antiepileptic drug treatment: outcomes and adherence. Pharmacotherapy. 2000;20:191S199S.

17. Eaddy MT, Cook CL, O’Day K, Burch SP, Cantrell $\mathrm{CR}$. How patient cost-sharing trends affect adherence and outcomes: a literature review. Pharmacy and Therapeutics. 2012;37(1):45-55.

18. Gagne JJ, Kesselheim AS, Choudhry NK, Polinski JM, Hutchins D, Matlin OS, et al. Comparative effectiveness of generic versus brand-name antiepileptic medications. Epilepsy Behav. 2015;52(Pt A):14-8.

19. Singal GL, Nanda A, Kotwani A. A comparative evaluation of price and quality of some branded 
versus branded-generic medicines of the same manufacturer in India. Indian $\mathbf{J}$ Pharmacol. 2011;43:131-6.

20. World Health Organisation. Essential drugs and medicines: Drug finance. Available at http://www.whoindia.org/EN/Section2/Section/Sectio n160_959.html. Accessed 12 September 2014.

21. Creese A, Kotwani A, Kutzin J, Pillay A. Evauating pharmaceuticals for health policy in low and middle income country settings. In: Freemantle N, Hill S, editors. Evaluating pharmaceuticals for health policy and reimbursement. Massachusetts, USA: Blackwell Publication; (in collaboration with WHO Geneva); 2004:227-43.

22. Frazier LM, Brown JT, Divine GW, Fleming GR, Philips NM, Siegal WC, et al. Can physician education lower the cost of prescription drugs? A prospective, controlled trial. Ann Intern Med. 1991;115(2):116-21.

Cite this article as: Shukla AK, Mehani R. Cost analysis of antiepileptic drugs available in India. Int J Basic Clin Pharmacol 2016;5:1636-40. 